\title{
Safety, pharmacokinetics, and biologic activity of pateclizumab, a novel monoclonal antibody targeting lymphotoxin $\alpha$ : results of a phase I randomized, placebo-controlled trial
}

Brinda Emu', Diana Luca', Carolyn Offutt', Jane L Grogan', Bernadette Rojkovich², Marna B Williams', Meina T Tang', Jim Xiao', June H Lee ${ }^{3}$ and John C Davis ${ }^{1 *}$

\begin{abstract}
Introduction: Pateclizumab (MLTA3698A) is a humanized mAb against lymphotoxin $\alpha$ (LTa), a transiently expressed cytokine on activated B and T cells (Th1, Th17), which are implicated in rheumatoid arthritis (RA) pathogenesis. This study was conducted to assess the safety, tolerability, < NOTE: For clarity and per AMA/S-W Style, please restore the use of Oxford/serial commas (ie: David likes vanilla, strawberry, and chocolate ice cream) throughout. and biologic activity of single and multiple doses of intravenous (IV) or subcutaneous (SC) pateclizumab in RA patients.
\end{abstract}

Methods: The single ascending dose (SAD) phase in patients with stable RA consisted of six cohorts (4:1 active: placebo at $0.3 \mathrm{mg} / \mathrm{kg} \mathrm{IV}, 1.0 \mathrm{mg} / \mathrm{kg} \mathrm{IV}, 1.0 \mathrm{mg} / \mathrm{kg} \mathrm{SC}, 3.0 \mathrm{mg} / \mathrm{kg} \mathrm{IV}, 3.0 \mathrm{mg} / \mathrm{kg} \mathrm{SC}$, and $5.0 \mathrm{mg} / \mathrm{kg} \mathrm{IV} ; n=5 /$ cohort). In the multiple ascending dose (MAD) phase, patients with prespecified RA disease activity received three doses of pateclizumab or placebo (4:1) every 2 weeks $(1.0 \mathrm{mg} / \mathrm{kg} \mathrm{SC}, n=10 ; 3.0 \mathrm{mg} / \mathrm{kg} \mathrm{SC}, n=20 ;$ or $5.0 \mathrm{mg} / \mathrm{kg} \mathrm{IV}, n=5)$. Safety and tolerability were assessed throughout, and clinical activity was determined after three doses (Week 6).

Results: We observed no serious adverse events (AEs) or dose-limiting toxicities, and the majority of AEs were mild to moderate. The pharmacokinetic profiles were linear, and clearance was independent of dose. Reductions in levels of serum CXCL13 were observed, supporting the biologic activity of pateclizumab on the LTa pathway. Patients receiving pateclizumab in the $3.0 \mathrm{mg} / \mathrm{kg}$ MAD group (3.0 mg/kg SC) demonstrated ACR20, ACR50, and ACR70 response rates at week 6 of $75 \%, 56 \%$ and $25 \%$, respectively, compared with $57 \%, 29 \%$, and $0 \%$ in the placebo group. The median Disease Activity Score in 28 joints, C-reactive protein, reduction was 28\% for pateclizumab, versus $8.4 \%$ for placebo.

Conclusions: Pateclizumabwas generally well-tolerated in RA patients. Preliminary evidence of clinical activity was observed in active RA patients at the dose level targeted for clinical effect.

\section{Introduction}

Rheumatoid arthritis (RA) is a systemic autoimmune inflammatory disease associated with progressive joint damage, pain, fatigue, and disability. Despite advances in the treatment of RA, a significant proportion of patients do not achieve an adequate clinical response upon treatment with available therapies, and less than half of

\footnotetext{
* Correspondence: davis.john@gene.com

'Genentech, Inc, 1 DNA Way, South San Francisco, CA 94080, USA Full list of author information is available at the end of the article
}

patients who do respond to therapy achieve complete remission [1]. Current biologic treatment options for the management of RA often target the proinflammatory cytokine TNF- $\alpha$; however, these agents are associated with safety concerns, such as increased risk of serious infection [2]. In addition, intolerance to or contraindication of an existing therapy may further limit a patient's therapeutic alternatives.

Depletion of cellular subsets implicated in RA immunopathogenesis has demonstrated significant clinical 
efficacy [3]. Novel therapies that both target the cellular source of multiple proinflammatory cytokines and interrupt the autoimmune inflammatory cycle perpetuated in RA could lead to improved outcomes compared to existing treatments.

Lymphotoxin $\alpha$ (LT $\alpha)$, a member of the TNF superfamily, is both secreted (as the homotrimer LT $\alpha 3$ ) and transiently expressed on the cell surface of activated B, Th1 and Th17 cells, where it forms a complex with LT $\beta$ as LT $\alpha 1 \beta 2$ heterotrimers [4-6] (Figure 1). Soluble LT $\alpha 3$ binds TNF receptor (TNFR) types I and II, whereas cellbound LT $\alpha 1 \beta 2$ heterotrimers bind LT $\beta$ receptors (LT $\beta R)$, resulting in the downstream secretion of proinflammatory cytokines and chemokines, such as chemokine (C-X-C motif) ligand 13 (CXCL13) [7]. In addition, signaling through the LT $\beta R$ pathway is required for the normal development of secondary lymph nodes and orchestration of robust germinal center architecture, and is also implicated in the development of ectopic lymphoid structures in chronically inflamed tissue [8].

LT $\alpha$ expression is also associated with the pathogenesis of RA. Ectopic lymphoid structures are present in synovial tissue from patients with RA [9], and both trimeric forms (LT $\alpha 3$ and $L T \alpha 1 \beta 2$ ) are elevated in the synovial fluid of patients with RA [10]. Furthermore, LT $\alpha, \mathrm{LT} \beta$ and LT $\beta \mathrm{R}$ transcripts are elevated in RA synovium [11-13].

A mouse-specific depleting mAb targeting surface $\mathrm{LT} \alpha$ has been shown to ameliorate inflammation and arthritis in murine models of disease [6]. In the collagen-induced arthritis (CIA) model, mouse anti-LTa efficacy has been attributed to depletion of Th1 and

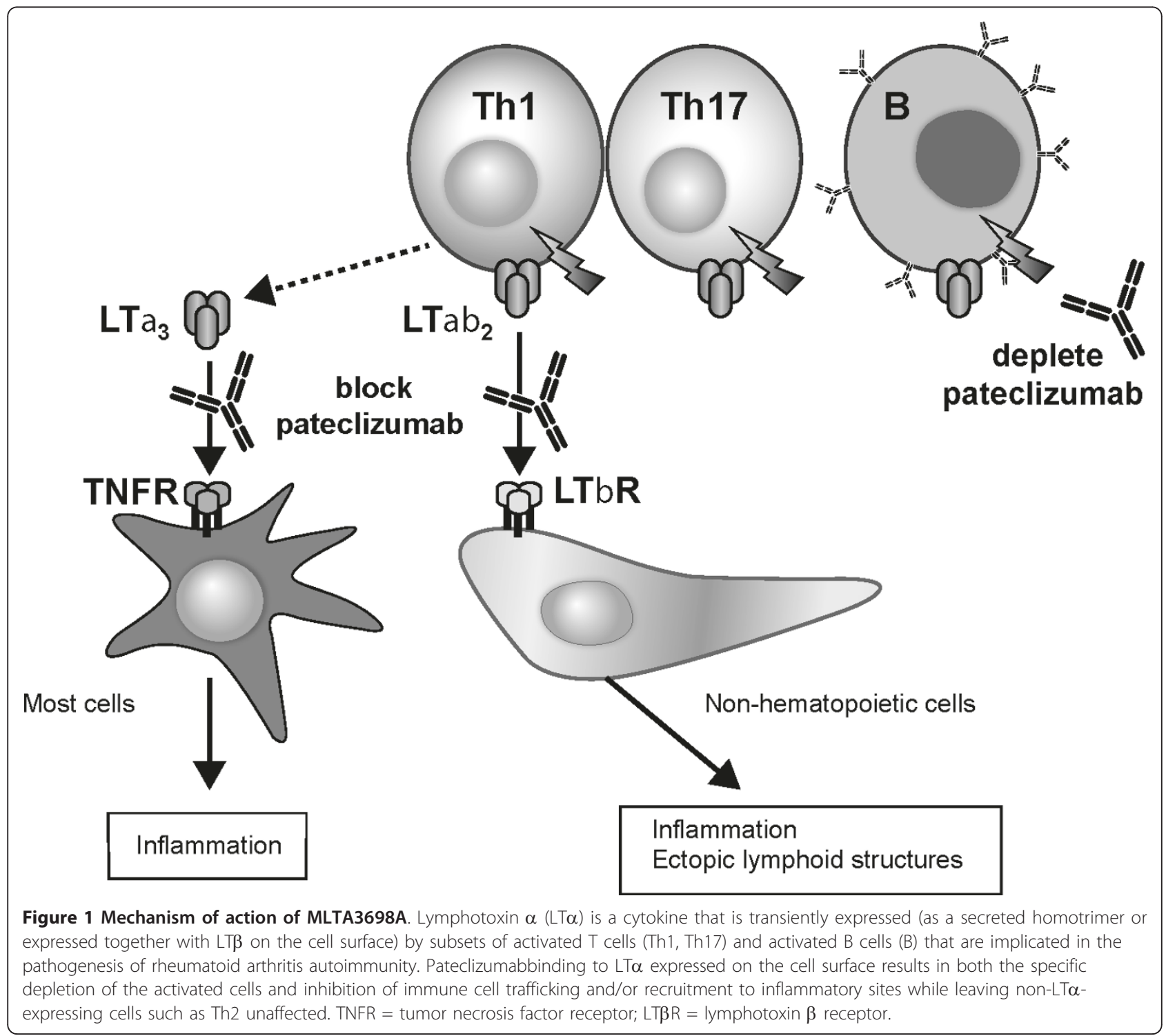


Th17 cells, which are T-cell subsets that express LTa and are pathogenic drivers of disease. To date there are no therapies that specifically target these $\mathrm{T}$-cell subsets.

Pateclizumab (MLTA3698A), a humanized mAb, specifically binds LT $\alpha$ in both the soluble LT $\alpha 3$ homotrimeric form and the surface-expressed $L T \alpha 1 \beta 2$ heterotrimer. Pateclizumab interferes with binding of LT trimers to its cognate receptors LT $\beta R$ and TNFR and has the potential to deplete subsets of LT $\alpha$-expressing cells. In this randomized, double-blind, placebo-controlled phase I study of 65 patients with active RA, we show the safety and activity of pateclizumab.

\section{Materials and methods}

We designed this randomized, double-blind, placebocontrolled trial to evaluate the safety, tolerability, pharmacokinetics (PK), pharmacodynamics (PD), and preliminary evidence of biologic activity of pateclizumab in patients with RA. Study participants were recruited from 26 centers in the United States and Hungary. The institutional review boards at each study site approved the protocol, and all subjects provided their written informed consent. The trial was registered under US National Institutes of Health ClinicalTrials.gov identifier NCT00888745.

\section{Patients}

Patients 18 to 75 years of age with a diagnosis of RA according to the American College of Rheumatology (ACR) 1987 revised criteria for RA [14] for at least 6 months were eligible for inclusion. Prior to randomization, patients must have been maintained on a stable disease-modifying antirheumatic drug (DMARD) regimen. Methotrexate up to $25 \mathrm{mg} /$ week for 4 weeks, leflunomide up to $20 \mathrm{mg} /$ day for 8 weeks, sulfasalazine up to $3 \mathrm{~g} /$ day for 6 weeks, hydroxychloroquine up to 400 $\mathrm{mg} /$ day for 8 weeks, or oral prednisone (or its equivalent) up to $10 \mathrm{mg} /$ day at a stable dose for 4 weeks, were permitted.

Patients enrolled in the single ascending dose (SAD) stage had RA and were being treated with a stable DMARD regimen without prespecified disease activity. Patients enrolled in the multiple ascending dose (MAD) stage were being treated with a stable DMARD regimen, had received previous treatment with no more than one biologic agent and were also required to have moderate RA disease as defined by a swollen joint count (SJC) $\geq 5$ (of 66), a tender joint count (TJC) $\geq 5$ (of 68), and Creactive protein $(\mathrm{CRP}) \geq 1.0 \mathrm{mg} / \mathrm{dl}$.

\section{Study design}

In the SAD phase of the study, 30 patients $(n=5 /$ cohort) were enrolled sequentially into six cohorts of five patients each (treatment allocation 4:1 pateclizumab:placebo) with four intravenous (IV) dose levels $(0.3,1.0,3.0$, and $5.0 \mathrm{mg} / \mathrm{kg}$ with 1 -hour IV infusion; cohorts $\mathrm{A}, \mathrm{B}, \mathrm{D}$ and $\mathrm{F}$, respectively) and two subcutaneous (SC) dose levels $(1.0$ and $3.0 \mathrm{mg} / \mathrm{kg}$; cohorts $\mathrm{C}$ and E) (Table 1). Patients were enrolled into the next dose cohort 14 days after administration of the study drug from the last patient in the previous dose cohort. All patients in the SAD phase were followed for 12 weeks after the last dose of the study drug, with followup visits at Weeks $2,4,6,8$, and 12 .

In the MAD phase of the study, 35 patients were enrolled sequentially into three cohorts with the same treatment allocation of 4:1 active:placebo $(1.0 \mathrm{mg} / \mathrm{kg} \mathrm{SC}$, $n=10 ; 3.0 \mathrm{mg} / \mathrm{kg} \mathrm{SC}, n=20$; and $5.0 \mathrm{mg} / \mathrm{kg} 1$-hour IV infusion, $n=5$; cohorts $\mathrm{G}, \mathrm{H}$, and I, respectively). Prior to enrollment of the MAD dose cohorts, all available safety data were reviewed for all patients from the SAD phase of the study through at least 14 days of follow-up. Patients in the MAD cohorts received three doses of the study drug at 2-week intervals $(0,2$, and 4 weeks). To enable detection of early clinical activity, 20 patients were enrolled in the target dose cohort $3.0 \mathrm{mg} / \mathrm{kg} \mathrm{SC}$ (16 patients received active drug and 4 received placebo). All patients were followed for 12 weeks after the last dose of the study drug, with follow-up visits at Weeks 6, 8, 10, 12, and 16 .

\section{Assessments}

\section{Safety}

Safety data were collected at each visit and graded according to the National Cancer Institute Common Toxicity Criteria Adverse Event version 3.0 (National Cancer Institute, Frederick, MD, USA).

\section{Pharmacokinetic assessments}

In the SAD phase of the study, PK serum samples were obtained at predose, 1 hour (IV only) and 4 hours after dosing on study day 1 , then on study Days $2,4,8,15$,

Table 1 Study schema for single-dose and multiple-dose escalation stages $^{\mathrm{a}}$

\begin{tabular}{lc}
\hline Stage dose and route & Patients, $\boldsymbol{n}$ (active:placebo) \\
\hline SAD stage dose, route (cohort) & \\
0.3 IV (A) & $4: 1$ \\
1.0 IV (B) & $4: 1$ \\
1.0 SC (C) & $4: 1$ \\
3.0 IV (D) & $4: 1$ \\
3.0 SC (E) & $4: 1$ \\
5.0 IV (F) & $4: 1$ \\
MAD stage dose, route (cohort) & \\
1.0 SC (G) & $8: 2$ \\
3.0 SC (H) & $16: 4$ \\
5.0 IV (I) & $4: 1$ \\
\hline
\end{tabular}

IV = intravenously; MAD = multiple ascending doses; SAD = single ascending dose; SC = subcutaneously. 
$22,29,43$, and 57 . In the MAD phase of the study, PK serum samples were obtained on Day 1 (predose, 1 hour postdose IV only); Days 4, 8, and 15 (predose, 1 hour after the end of the IV infusion only); Days 18 and 29 (predose 1 and 4 hours after the end of the IV infusion only); and Days 30, 32, 36, 43, 57, 71, and 85. PK samples were analyzed using a validated ELISA with a lower limit of quantification of $100 \mathrm{ng} / \mathrm{ml}$.

For anti-therapeutic antibody measurement, serum samples were collected at Day 1 (predose), 29 (predose), and 57 in the SAD stage. For the MAD stage, samples were collected at Day 1 (predose), 29 (predose), 57, and 85 . On the basis of the assay validation data, the measured anti-pateclizumab responses are not likely to be enhanced by soluble LT $\alpha$ cross-reactivity, and the assay is formatted appropriately to reduce drug interference (data not shown).

\section{Pharmacodynamic biomarker assessments}

In the SAD phase of the study, PD serum samples were obtained at screening, Day 1 (predose) and Days 2, 4, 8, $15,22,29,43$, and 57 . In the MAD phase of the study, serum samples were obtained at screening, Day 1 (predose) and Days 8, 15, 29, 36, 43, 57, 71, and 85. In all cohorts, levels of CXCL13 and total soluble LTa (free and drug bound LT $\alpha$, which may include all trimeric forms) were assessed by ELISA with lower limits of quantification of $15.6 \mathrm{pg} / \mathrm{ml}$ and $100 \mathrm{pg} / \mathrm{ml}$, respectively.

\section{Clinical activity assessments}

Exploratory analyses were conducted for the MAD stage to evaluate the effect of pateclizumab on the clinical response variables, including ACR20 and ACR50 (20\% and $50 \%$ improvement, respectively, in tender or SJCs, as well as $20 \%$ and $50 \%$ improvement, respectively, in three of the other five American College of Rheumatology criteria for RA), Disease Activity Score in 28 joints (DAS28) responses and C-reactive protein (CRP) These analyses were performed at week 6 , two weeks after the last dose of study drug.

\section{Statistical analysis}

All patients who received at least one dose of the study drug were included in the safety, PK, and PD analyses. Adverse events (AEs), vital signs, laboratory tests, PK, and evidence of biologic activity were descriptively compared across the various treatment groups with no formal statistical testing.

For disease activity measurements, data were censored for patients who received a new or increased dose of a DMARD or who withdrew from the study. For all patients who received pateclizumab, censored data were imputed as the highest disease activity score in the corresponding cohort at the corresponding time point for active patients (or lowest activity for that patient, whichever was lower). For patients who received placebo, censored data were imputed as the last observation recorded for that patient.

PK was assessed by noncompartmental analysis using WinNonlin Professional version 5.2.1 software (Pharsight, Mountain View, CA, USA). Preliminary population PK modeling was conducted to estimate the bioavailability following SC dosing using all the available SAD and MAD PK data (NONMEM 7.2, ICON Development Solutions, Ellicott City, MD, USA).

\section{Results}

\section{Study population}

Of the 65 patients enrolled in the study, 45 patients were from the United States and 20 patients were from Hungary. Patient demographics were balanced between active drug and placebo recipients (Table 2) in both the SAD and the MAD stages of the study. As anticipated based on the inclusion criteria, patients in the MAD phase of the study had greater baseline disease activity than patients in the SAD phase. At baseline, patients in the MAD phase of the study had had a diagnosis of RA for a median of 8 years $(\mathrm{IQR}=4$ to 11 , range $=0.6$ to 30), with a median baseline CRP of $1.7 \mathrm{mg} / \mathrm{dL}$ (IQR = 1.3 to 3 , range $=0.9$ to 4.6 ), median erythrocyte sedimentation rate of $31 \mathrm{~mm} / \mathrm{hr}(\mathrm{IQR}=24$ to 64 , range $=$ 11 to 97$)$, median SJC of $9(\mathrm{IQR}=9$ to 16 , range $=5$ to $45)$, median TJC of 17 (IQR $=11$ to 31 , range $=5$ to $65)$ and a median DAS28-CRP score of $5.6(\mathrm{IQR}=4.9$ to 5.9 , range $=3.9$ to 7.9 ). In addition, in the MAD phase of the study, patients who received pateclizumab had higher baseline disease activity based on SJCs and TJCs, as well as higher CRP measurements.

\section{Patient disposition}

Overall, 97\% of patients in the pateclizumab-treated groups and $100 \%$ of patients in the placebo groups completed the study. One patient in cohort G (MAD $1 \mathrm{mg} /$ $\mathrm{kg} \mathrm{SC)}$ who received active drug discontinued the study at day 20 because of an RA flare after having received two doses of the study drug. Clinical activity data were censored for an additional seven patients in the MAD phase of the study ( 6 of 28 receiving pateclizumab and 1 of 7 receiving placebo) who received adjunctive steroid therapy during the course of the study.

\section{Safety}

Pateclizumabwas well-tolerated during the study. There were no serious AEs and no dose-limiting toxicities. No AEs resulted in the withdrawal of the study drug. Twenty patients in the SAD phase reported a total of 44 AEs. The overall incidence of AEs was slightly higher in pateclizumab-treated patients than in placebo-treated patients ( $71 \%$ and $50 \%$, respectively) (Table 3$)$. Twenty patients in the MAD phase reported a total of 54 AEs, 
Table 2 Baseline patient demographic and disease characteristics ${ }^{a}$

\begin{tabular}{|c|c|c|c|c|c|c|c|}
\hline \multirow[b]{2}{*}{$\begin{array}{l}\text { Demographics and disease } \\
\text { characteristics }\end{array}$} & \multicolumn{2}{|r|}{ SAD } & \multicolumn{5}{|c|}{ MAD } \\
\hline & $\begin{array}{l}\text { Placebo } \\
(n=6)\end{array}$ & $\begin{array}{c}\text { All } \\
\text { pateclizumab } \\
(n=24)\end{array}$ & $\begin{array}{l}\text { Placebo } \\
(n=7)\end{array}$ & $\begin{array}{c}1.0 \mathrm{mg} / \mathrm{kg} \\
\mathrm{SC} \\
(n=8)\end{array}$ & $\begin{array}{c}3.0 \mathrm{mg} / \mathrm{kg} \\
\mathrm{SC} \\
(n=16)\end{array}$ & $\begin{array}{c}5.0 \mathrm{mg} / \mathrm{kg} \\
\mathrm{IV} \\
(n=4)\end{array}$ & $\begin{array}{c}\text { All } \\
\text { pateclizumab } \\
(n=28)\end{array}$ \\
\hline \multicolumn{8}{|l|}{ Demographics } \\
\hline Sex, female:male & $6: 0$ & $20: 4$ & $7: 0$ & $6: 2$ & $14: 2$ & $3: 1$ & 23:5 \\
\hline Median age, years (range) & $\begin{array}{c}57 \\
(25 \text { to } 69)\end{array}$ & $\begin{array}{c}57.5 \\
(35 \text { to } 75)\end{array}$ & $\begin{array}{c}57 \\
\text { (29 to 69) }\end{array}$ & $\begin{array}{c}56 \\
(41 \text { to } 73)\end{array}$ & $\begin{array}{c}56 \\
(23 \text { to } 70)\end{array}$ & $\begin{array}{c}54 \\
\text { (48 to } 61)\end{array}$ & $\begin{array}{c}57 \\
(23 \text { to } 73)\end{array}$ \\
\hline Race, white:black & $5: 1$ & 23:1 & 7:0 & $7: 1$ & $16: 0$ & $3: 1$ & $26: 2$ \\
\hline Region, USA:Hungary & All USA & All USA & $3: 4$ & $6: 2$ & 5:11 & $2: 2$ & 13:15 \\
\hline \multicolumn{8}{|l|}{ Disease characteristics } \\
\hline Median disease duration, years & 3 & 5 & 5.4 & 9 & 7.5 & 7 & 8 \\
\hline RF- and anti-CCP-positive (\%) & 17 & 67 & 71.4 & 87.5 & 87.5 & 50.0 & 82.1 \\
\hline \multicolumn{8}{|l|}{ Concomitant medications (\%) } \\
\hline Prior anti-TNF- $\alpha$ & 33 & 33 & 0 & 25 & 19 & 0 & 18 \\
\hline MTX & 67 & 63 & 29 & 13 & 44 & 50 & 36 \\
\hline Leflunomide & 0 & 4 & 43 & 38 & 6 & 25 & 18 \\
\hline Steroids & 33 & 25 & 57 & 50 & 69 & 75 & 54 \\
\hline Median CRP, mg/dl (IQR) & $\begin{array}{l}0.2 \\
(0.1 \text { to } \\
1.1)\end{array}$ & $\begin{array}{c}0.7 \\
(0.0 \text { to } 6.2)\end{array}$ & $\begin{array}{c}1.6 \\
(1.2 \text { to } \\
3.3)\end{array}$ & $\begin{array}{c}2.1 \\
(1.1 \text { to } 4.6)\end{array}$ & $\begin{array}{c}1.6 \\
\text { (0.9 to } 4.5)\end{array}$ & $\begin{array}{l}3.7 \\
\text { (0.9 to } 4.4)\end{array}$ & $\begin{array}{c}2 \\
(0.9 \text { to } 4.6)\end{array}$ \\
\hline Median ESR, mm/hour (IQR) & $\begin{array}{c}25.5 \\
(12 \text { to } 48)\end{array}$ & $\begin{array}{c}27 \\
\text { (2 to } 59)\end{array}$ & $\begin{array}{c}34 \\
\text { (24 to } 65)\end{array}$ & $\begin{array}{c}42.6 \\
(14 \text { to } 86)\end{array}$ & $\begin{array}{c}31 \\
\text { (11 to } 97)\end{array}$ & $\begin{array}{c}39.5 \\
(22 \text { to } 66)\end{array}$ & $\begin{array}{c}30.5 \\
(11 \text { to } 97)\end{array}$ \\
\hline Median SJC (range) & $\begin{array}{c}12 \\
\text { (6 to } 26)\end{array}$ & $\begin{array}{c}14.5 \\
(0 \text { to } 34)\end{array}$ & $\begin{array}{c}6 \\
\text { (5 to } 12)\end{array}$ & $\begin{array}{c}13 \\
\text { (6 to } 23)\end{array}$ & $\begin{array}{c}7 \\
(5 \text { to } 35)\end{array}$ & $\begin{array}{c}12 \\
(5 \text { to } 45)\end{array}$ & $\begin{array}{c}10.5 \\
(5 \text { to } 45)\end{array}$ \\
\hline Median TJC (range) & $\begin{array}{c}19 \\
(12 \text { to } 38)\end{array}$ & $\begin{array}{c}27.5 \\
(0 \text { to } 66)\end{array}$ & $\begin{array}{c}11 \\
\text { (5 to } 33)\end{array}$ & $\begin{array}{c}22 \\
(5 \text { to } 60)\end{array}$ & $\begin{array}{c}20 \\
\text { (7 to } 65)\end{array}$ & $\begin{array}{c}30 \\
(12 \text { to } 56)\end{array}$ & $\begin{array}{c}19.5 \\
(5 \text { to } 65)\end{array}$ \\
\hline Median baseline DAS28-CRP (IQR) & $\begin{array}{l}4.8 \\
(4.6 \text { to } \\
5.5)\end{array}$ & $\begin{array}{c}5.4 \\
(2.19 \text { to } 7.2)\end{array}$ & $\begin{array}{l}5.7 \\
(3.9 \text { to } \\
6.0)\end{array}$ & $\begin{array}{c}6.0 \\
(4.8 \text { to } 7.9)\end{array}$ & $\begin{array}{c}5.4 \\
(4.0 \text { to } 7.5)\end{array}$ & $\begin{array}{l}5.7 \\
(4.2 \text { to } 7.0)\end{array}$ & $\begin{array}{c}5.6 \\
(3.9 \text { to } 7.9)\end{array}$ \\
\hline
\end{tabular}

${ }^{\mathrm{a} C C P}=$ cyclic citrullinated peptide; CRP = C-reactive protein; DAS28-CRP = Disease Activity Score in 28 joints, C-reactive protein; ESR = erythrocyte sedimentation rate; IV = intravenously; $M A D=$ multiple ascending dose; $M T X=$ methotrexate; $R A=$ rheumatoid arthritis; $\mathrm{RF}=$ rheumatoid factor; $S A D=$ single ascending dose; SC = subcutaneously; SJC = swollen joint count; TJC = tender joint count.

with both treatment groups experiencing comparable rates of AEs (57\% in pateclizumab-treated patients and $57 \%$ in placebo-treated patients). Nearly all (97\%) of the AEs were grade 1 or 2 . All three grade 3 AEs in patients receiving pateclizumabwere reported as unrelated to study drug administration.

There was no trend toward an increased incidence of AEs with increasing doses of pateclizumab. The most

Table 3 Treatment-emergent adverse events by preferred term occurring in at least two patients from all pateclizumab-treated groups combined during either single or multiple ascending dose phases ${ }^{\mathrm{a}}$

\begin{tabular}{|c|c|c|c|c|c|c|c|}
\hline \multirow[b]{2}{*}{ Adverse events } & \multicolumn{2}{|c|}{ SAD cohorts, $n(\%)$} & \multicolumn{5}{|c|}{ MAD cohorts, $n(\%)$} \\
\hline & $\begin{array}{c}\text { Placebo } \\
(n=6)\end{array}$ & $\begin{array}{c}\text { All active } \\
(n=24)\end{array}$ & $\begin{array}{c}\text { Placebo } \\
(n=7)\end{array}$ & $\begin{array}{c}1.0 \mathrm{mg} / \mathrm{kg} \mathrm{SC} \\
(n=8)\end{array}$ & $\begin{array}{c}3.0 \mathrm{mg} / \mathrm{kg} \mathrm{SC} \\
(n=16)\end{array}$ & $\begin{array}{c}5.0 \mathrm{mg} / \mathrm{kg} \mathrm{IV} \\
(n=4)\end{array}$ & $\begin{array}{c}\text { All active } \\
(n=28)\end{array}$ \\
\hline Any event & $3(50.0)$ & $20(66.7)$ & $4(57.1)$ & $7(87.5)$ & $8(50.0)$ & $1(25.0)$ & $20(57.1)$ \\
\hline Fatigue & $0(0.0)$ & $2(8.3)$ & $1(14.3)$ & $0(0.0)$ & $0(0.0)$ & $0(0.0)$ & $0(0.0)$ \\
\hline Rheumatoid arthritis & $0(0.0)$ & $2(8.3)$ & $0(0.0)$ & $1(12.5)$ & $1(6.3)$ & $0(0.0)$ & $2(7.1)$ \\
\hline Rash & $0(0.0)$ & $2(8.3)$ & $0(0.0)$ & $0(0.0)$ & $0(0.0)$ & $0(0.0)$ & $0(0.0)$ \\
\hline Diarrhea & $0(0.0)$ & $1(4.2)$ & $0(0.0)$ & $3(37.5)$ & $1(6.3)$ & $0(0.0)$ & $4(14.3)$ \\
\hline Vomiting & $0(0.0)$ & $0(0.0)$ & $0(0.0)$ & $2(25.0)$ & $0(0.0)$ & $0(0.0)$ & $2(7.1)$ \\
\hline Nasopharyngitis & $0(0.0)$ & $0(0.0)$ & $0(0.0)$ & $0(0.0)$ & $2(12.5)$ & $0(0.0)$ & $2(7.1)$ \\
\hline Headache & $0(0.0)$ & $1(4.2)$ & $0(0.0)$ & $2(25.0)$ & $1(6.3)$ & $1(25.0)$ & $4(14.3)$ \\
\hline Rhinorrhea & $0(0.0)$ & $0(0.0)$ & $0(0.0)$ & $1(12.5)$ & $1(6.3)$ & $0(0.0)$ & $2(7.1)$ \\
\hline
\end{tabular}

${ }^{\mathrm{a}} \mathrm{IV}=$ intravenously; $\mathrm{MAD}=$ multiple ascending dose; $\mathrm{SAD}=$ single ascending dose; $\mathrm{SC}=$ subcutaneously. 
common AEs reported in the active arm were musculoskeletal, gastrointestinal, and headache. There was a single injection site reaction in a patient who experienced injection site pain in the $3.0 \mathrm{mg} / \mathrm{kg} \mathrm{SC}$ cohort in the SD stage of the study. There were no increased rates of infections in patients receiving pateclizumabcompared to placebo. In addition, there were no significant differences over time in total lymphocytes, $\mathrm{T}$ cells, or B cells between patients receiving pateclizumabcompared to placebo (data not shown).

\section{Immunogenicity}

Of the 52 patients treated with pateclizumab, anti-pateclizumabantibodies were detected in a total of seven patients. In the IV cohorts, 1 of 20 patients was antipateclizumabantibody-positive. In the SC groups, 6 of 32 patients were anti-pateclizumabantibody-positive. There were no anti-pateclizumabantibodies detected in placebo-treated patients or at any predose time points.

\section{Efficacy outcomes}

Clinical activity was assessed at Week 6, 2 weeks after the last dose of the study drug. Cohort $\mathrm{H}$ was used for evaluation of biologic activity based on the dose (3.0 $\mathrm{mg} / \mathrm{kg} \mathrm{SC})$ and expanded sample size $(n=20)$. Baseline disease activity scores, as measured by DAS28-CRP and CRP, were comparable between those patients receiving pateclizumabin cohort $\mathrm{H}$ and patients receiving placebo (pooled placebo data across all MAD cohorts).

A total of $75 \%, 56 \%$, and $25 \%$ of patients treated with $3 \mathrm{mg} / \mathrm{kg}$ pateclizumabSC achieved an ACR20, ACR50, and ACR70 responses, respectively (Figure $2 \mathrm{~A}$ ). In comparison, $57 \%, 29 \%$, and $0 \%$ of the patients receiving placebo achieved ACR20, ACR50, and ACR70 scores. Patients receiving pateclizumaband placebo had median baseline DAS28-CRP scores of 5.44 and 5.69. At week 6, patients receiving pateclizumabhad a median DAS28CRP score of 3.47 with a median reduction of 1.22 . Placebo patients' median score was 4.86 , with a median reduction of 0.82 (Figure 2B). At Week 6, median CRP measurements had decreased $28 \%$ from baseline in pateclizumab-treated patients compared to $8 \%$ among placebo-treated patients (Figure $2 \mathrm{C}$ ). Patients receiving multiple doses pateclizumabat $3.0 \mathrm{mg} / \mathrm{kg} \mathrm{SC}$ indicated preliminary evidence of clinical activity on all three prespecified end points. When patients were followed to Week 10 (6 weeks after the last dose of the study drug), ACR50 responses were sustained, with $50 \%$ of patients receiving pateclizumabmaintaining an ACR50 response compared with $14 \%$ of placebo-treated patients (Figure 2D).

Patients receiving pateclizumabin a lower-dose MAD cohort (cohort G, $1.0 \mathrm{mg} / \mathrm{kg} \mathrm{SC} ; n=10$ ) did not show evidence of clinical activity. Data from two patients were imputed (one patient received prednisone on day 2 of the study and another withdrew after two doses because of RA flare). Thus, at the 6-week end point, our sample size was too limited for characterization of efficacy. In the highest-dose cohort (cohort I, $5.0 \mathrm{mg} / \mathrm{kg} \mathrm{IV}$ ), the presence of clinical activity was observed in a single patient (one of four receiving pateclizumab) with an ACR70 score; however, the interpretation of a dose response is limited because of the small number of patients in this cohort.

In the expanded cohort $(3.0 \mathrm{mg} / \mathrm{kg} \mathrm{SC}), 7$ of 16 patients were taking methotrexate and 3 of 16 patients had previously received TNF blockade. There was no clear difference in efficacy based on the use of methotrexate. Four of seven patients taking methotrexate achieved a score of ACR50, whereas three of nine patients not receiving methotrexate achieved an ACR50 score. The median reductions from baseline in DAS28CRP scores were 1.37 and 1.07 (mean reductions in DAS28-CRP of 0.84 and 1.04,) in those who were and were not receiving methotrexate. Of the three patients who had previously received TNF blockade, none achieved an ACR50 score. Four patients in the $3.0 \mathrm{mg} /$ kg SC expanded cohort developed anti-pateclizumabantibodies. Three of these patients also achieved an ACR50 score, despite the development of antipateclizumabantibodies.

\section{Pharmacokinetics}

Pateclizumabconcentration and time profiles displayed biexponential decay after IV administration (Figure 3A). Overall, pateclizumabexposure, as measured by maximum serum concentration $\left(C_{\max }\right)$ and area under the concentration time curve (AUC), were approximately dose-proportional after single or multiple doses. After a single dose, the cohort mean clearance $(\mathrm{CL})$ and terminal half-life $\left(\mathrm{t}_{1 / 2}\right)$ ranged from 4.54 to $7.03 \mathrm{ml} /$ day $/ \mathrm{kg}$, and 8 to 15 days, respectively. The bioavailability following SC dosing was approximately $43 \%$. After three doses of pateclizumabat 1 or $3 \mathrm{mg} / \mathrm{kg} \mathrm{SC}$, or $5 \mathrm{mg} / \mathrm{kg} \mathrm{IV}$ at 2week intervals $(0,2$, and 4 weeks), the mean accumulation index ranged from 1.77 to 1.88 . The mean CL and $t_{1 / 2}$ values from the MAD cohorts were similar to those from the SAD cohorts.

\section{Pharmacodynamics}

Decreases in CXCL13 after administration of pateclizumabwere observed in the SAD and MAD phases in all cohorts receiving doses $\geq 1 \mathrm{mg} / \mathrm{kg}$ pateclizumab (Figure 3B). Decreases in CXCL13 levels following pateclizumabadministration indicated biological activity. Increases in soluble LT $\alpha$ were observed in all cohorts given anti$\mathrm{LT} \alpha$, with minimal elevation at the lowest doses $(0.3$ $\mathrm{mg} / \mathrm{kg} \mathrm{IV}$ and $1 \mathrm{mg} / \mathrm{kg} \mathrm{SC}$ ) and no changes in the 


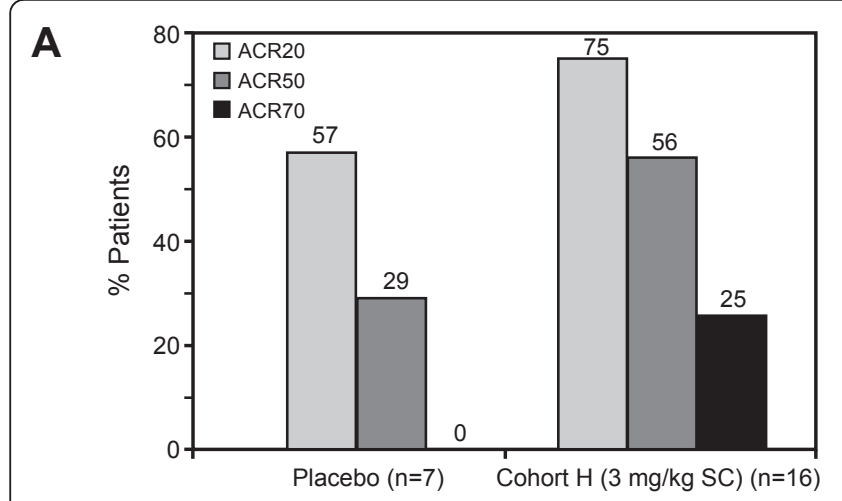

B
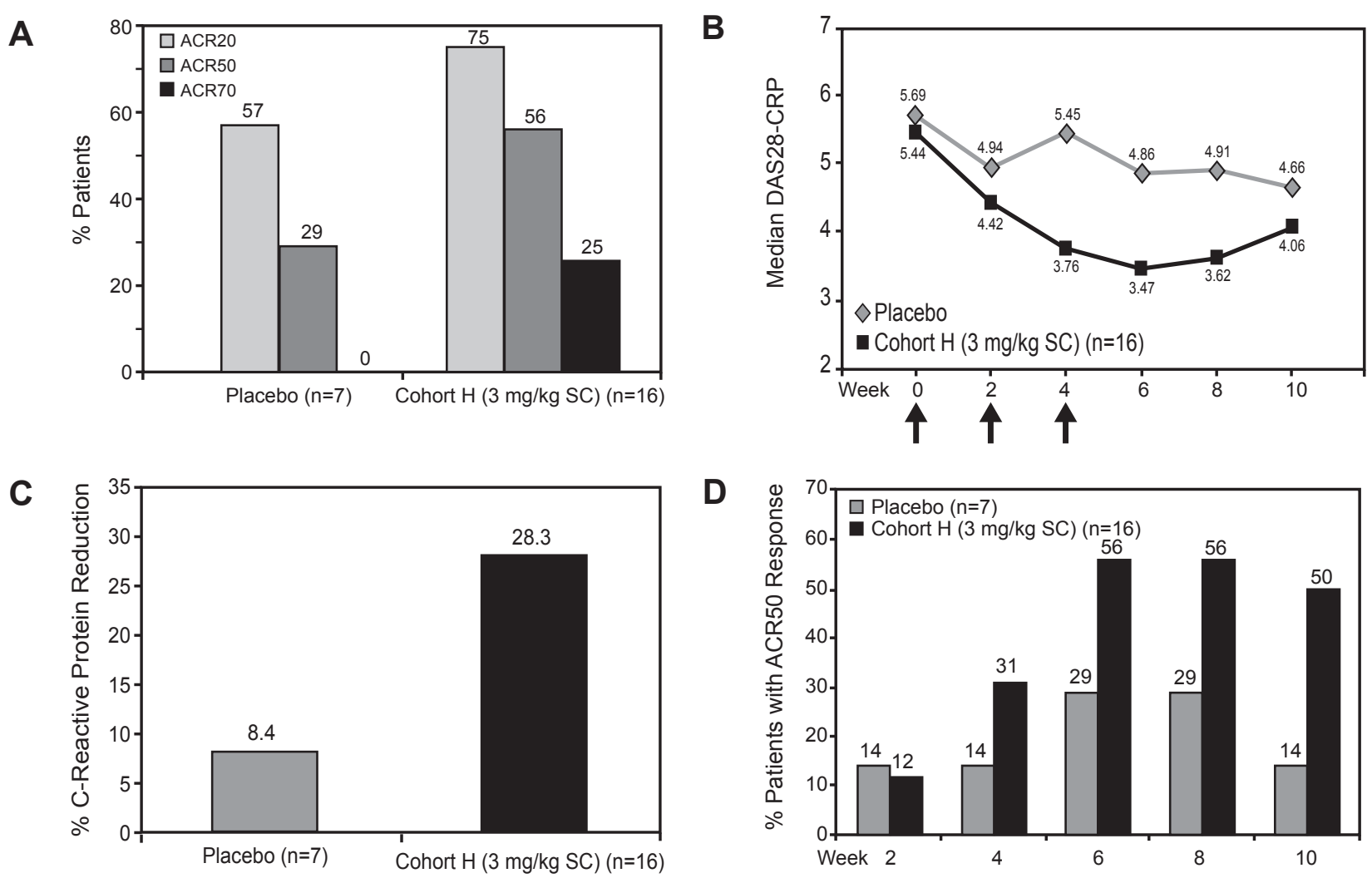

Figure 2 Clinical activity in patients receiving $3 \mathbf{~ m g} / \mathbf{k g}$ SC pateclizumabor placebo. ACR20, ACR50 and ACR70 = 20\%, 50\% and 70\% improvement, respectively, in tender or swollen joint counts, as well as 20\%,50\% and $70 \%$ improvement, respectively, in three of the other five American College of Rheumatology criteria for rheumatoid arthritis; DAS28-CRP = Disease Activity Score in 28 joints, C-reactive protein; SC = subcutaneously.

placebo group. Maximal increases occurred at $3 \mathrm{mg} / \mathrm{kg}$ SC. These results are consistent with the expected formation of pateclizumab-LT $\alpha$ complexes and an increased half-life of soluble LT $\alpha$ upon binding to pateclizumab. Similar results were observed in preclinical studies in cynomolgus monkeys [15].

\section{Correlative analysis of pharmacodynamics and pharmacokinetics}

Maximum decreases in CXCL13 (PD effects) were consistently observed at serum drug concentrations of $\geq 1$ to $10 \mu \mathrm{g} / \mathrm{ml}$ across all anti-LT $\alpha$ cohorts with $\geq 1 \mathrm{mg} / \mathrm{kg}$ doses (Additional file 1). There was no apparent correlation between decreases in CXCL13 and pateclizumabCmax, or AUC.

\section{Discussion}

In this phase I study, pateclizumab, a humanized mAb that specifically binds LT $\alpha$, was well-tolerated in patients with active RA. Using an expanded cohort approach, preliminary evidence of clinical activity was observed at the prespecified target dose of $3 \mathrm{mg} / \mathrm{kg} \mathrm{SC}$ as measured by reduction in DAS28-CRP scores, reduction of CRP values, and achievement of ACR20, ACR50, and ACR70 responses. PK data revealed linear biphasic kinetics with dose proportionality. CXCL13 reduction as a PD marker was observed, supporting the anticipated effect of pateclizumabon downstream signaling via the LT $\alpha$ pathway.

Pateclizumabis a humanized mAb against the cytokine LT $\alpha$. It is thought to act both by selectively depleting a specific subset of LT $\alpha$-expressing activated T and B cells and by blocking LT $\alpha$-mediated signaling (Figure 1). LT $\alpha$ is expressed on subsets of Th1 and Th17 T cells, as well as on activated B cells, but is absent from other subsets, such as Th2 [6]. Pateclizumablikely exerts its effects farther upstream than TNF inhibitors by targeting the cellular source of multiple proinflammatory cytokines. In a preclinical model of CIA, a murine antibody targeting LT $\alpha$ showed clinical efficacy by specifically depleting LT $\alpha$-expressing lymphocytes, resulting in decreased joint pathology and rapid reduction of TNF$\alpha$, IL- $1 \beta$ and IL- 6 levels within the hindpaw [6]. Importantly, the murine antibody had no effect in a Th2-driven model of asthma, demonstrating selectivity of antiLT $\alpha$ for Th1 and Th17 cells. 


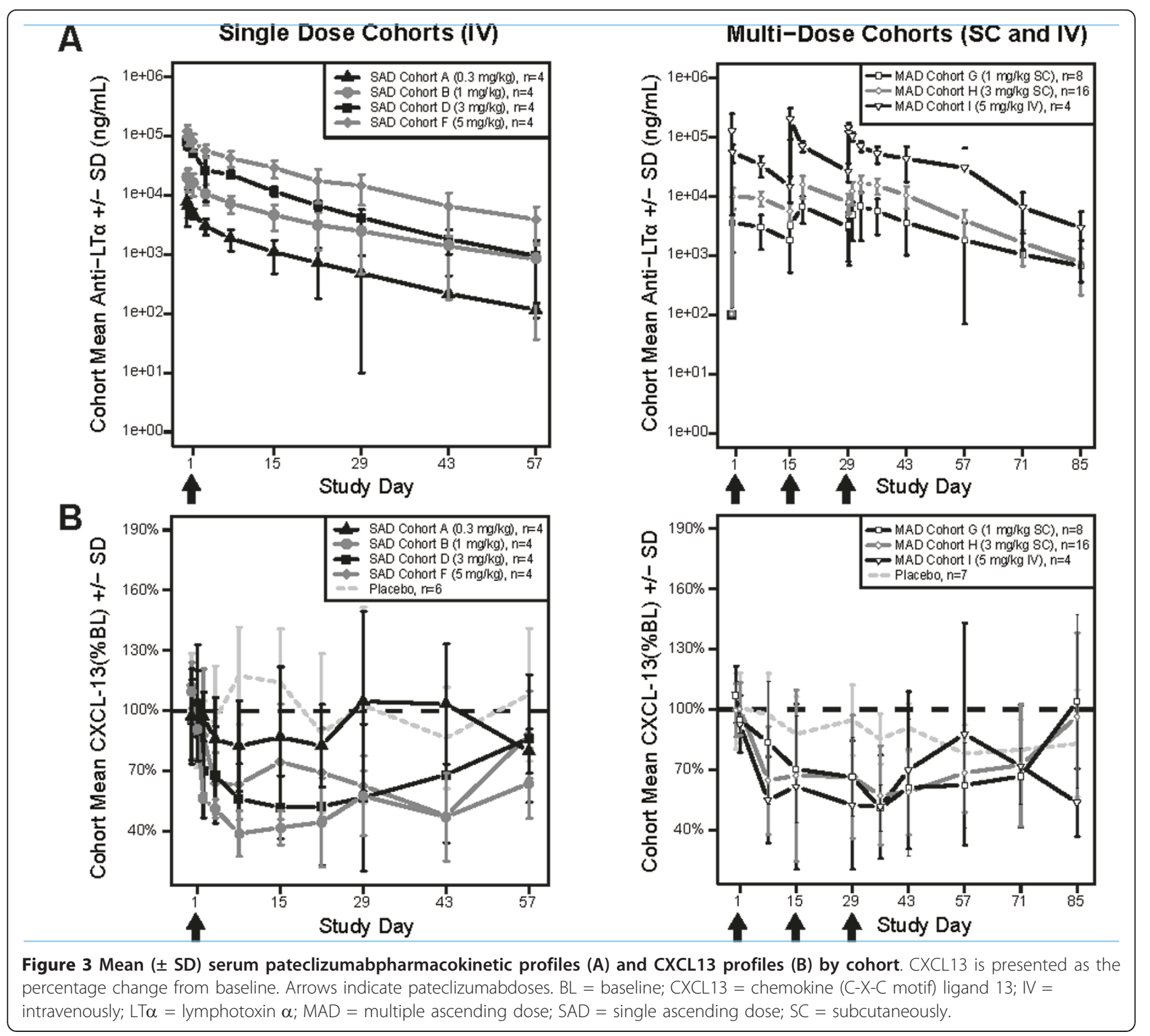

This phase I study of patients with moderate to severe RA was designed to assess the safety and tolerability of pateclizumaband to evaluate preliminary evidence of clinical activity. pateclizumabwas well-tolerated in patients receiving IV or SC administration of either single or multiple doses. The majority of AEs were grade 1 or 2, with no serious AEs and no withdrawal of the study drug due to AEs. Importantly, no serious infections were reported during the study, and no increased rate of infections was reported in patients receiving pateclizumabcompared with placebo. PK analysis revealed that exposure to pateclizumabwas approximately dose-proportional. Anti-pateclizumabantibodies were detected in 7 of 52 pateclizumab-treated patients, but without any clinical sequelae.
CXCL13 is a chemokine induced downstream of LT $\beta$ R signaling which has been implicated in the formation of ectopic lymphoid structures [11,12,16]. Elevated CXCL13 serum levels have been associated with synovitis in RA [17], and serum CXCL13 is decreased following treatment of RA patients with TNF- $\alpha$ inhibitors and anti-CD20 rituximab [17-19], thus implicating CXCL13 as a robust biomarker of RA disease activity. In our PD evaluations, pateclizumabadministration maximally decreased CXCL13 levels in all dose cohorts $\geq 1.0 \mathrm{mg} /$ $\mathrm{kg} \mathrm{SC}$ or IV. The reduction in CXCL13 most likely reflects an effect on downstream events following interruption of the LT $\alpha$ pathway.

The $3.0 \mathrm{mg} / \mathrm{kg} \mathrm{SC}$ cohort in the MAD phase of the study consisted of an expanded cohort designed to 
evaluate clinical activity of pateclizumabat the target dose. Clinical response variables were assessed at week 6 ( 2 weeks after the last dose of drug). ACR20, ACR50, and ACR70 response rates were seen in $75 \%, 55 \%$, and $25 \%$ of patients. In addition to ACR20, ACR50, and ACR70 responses achieved in this patient cohort, these patients showed substantial decreases in DAS28-CRP scores and CRP levels compared to placebo-treated subjects. Overall, for all measures evaluated, there was preliminary evidence of clinical activity in patients receiving pateclizumabcompared to placebo. Furthermore, evidence of sustained clinical activity was observed, with $50 \%$ of patients maintaining an ACR50 score up to 6 weeks after receiving their last dose of the study drug. The concomitant use of methotrexate did not affect clinical activity results. None of the three patients who had previously received TNF blockade achieved an ACR50 score. However, the small number of these patients limits the interpretation of activity in these subpopulations of patients who may be receiving (or may have received) other medications targeting RA disease.

The limitations of this study include the small sample size, which restricts interpretation of the study results. Regarding clinical activity, the other MAD dose cohorts $(1.0 \mathrm{mg} / \mathrm{kg} \mathrm{SC}$ and $5.0 \mathrm{mg} / \mathrm{kg} \mathrm{IV})$ were not designed as expanded cohorts, thus the ability to detect a dose response was limited by the small number of patients within these cohorts. In addition, patients were recruited from only two countries for this study (the United States and Hungary). Larger global studies will allow the evaluation of the effect of pateclizumabacross a broader RA patient population. Baminercept (a human LT $\beta$ R-human immunoglobulin G1 (IgG1) fusion protein) failed to show clinical benefit in a phase II trial in patients with RA [20,21]. Although both pateclizumaband baminercept block LT $\alpha \beta$-induced signaling (via the LT $\beta$ receptor) [7], it is important to note that pateclizumabis distinct in its potential to selectively deplete LT $\alpha$ expressing cells. In a preclinical murine model of established arthritis, a depleting murine anti-LT $\alpha$ antibody had efficacy comparable to that of anti-TNF- $\alpha$ antibodies, whereas an LT $\beta R /$ Ig blocker had no effect [6]. In addition, this murine antibody demonstrated efficacy in mice that were refractory to anti-TNF administration [22]. Together these data suggest that the depleting anti-LT $\alpha \mathrm{mAb}$ pateclizumabhas great potential for clinical activity in RA.

\section{Conclusions}

Inhibition of the LT $\alpha$ pathway provides a unique approach by which to abrogate proinflammatory responses in RA pathology. By blocking signaling through the LT $\alpha$ pathway, as well as by depleting LT $\alpha$ expressing cells, which are dominant sources of TNF- $\alpha$ and IL-6, pateclizumabis likely to work upstream of TNF- $\alpha$ blockade. This mechanism may provide an attractive alternative therapeutic approach for patients with moderate to severe RA. In this phase I study, pateclizumabwas well-tolerated and provided a linear PK profile when delivered subcutaneously. Given preliminary evidence of biologic and clinical activity, further evaluation of its clinical efficacy is warranted in larger clinical trials. To further characterize the safety, PK, PD and clinical activity of pateclizumab, a phase II study of RA patients without an adequate response to DMARDs is in progress.

\section{Additional material}

Additional file 1: Maximum decreases in CXCL13 (pharmacodynamic effects) were consistently observed at serum pateclizumabconcentrations $>1$ to $10 \mu \mathrm{g} / \mathrm{ml}$ across all cohorts. The pateclizumab (circles) and CXCL13 (triangles) concentrations are presented as means \pm SD.

\begin{abstract}
Abbreviations
ACR: American College of Rheumatology; AE: adverse event; anti-CCP: anticyclic citrullinated peptide; AUC: area under the concentration time curve; CIA: collagen-induced arthritis; $C L$ : mean clearance; $C_{\text {max }}$ : maximum serum concentration; CRP: C-reactive protein; DAS28-CRP: Disease Activity Score in 28 joints, C-reactive protein; DMARD: disease-modifying antirheumatic drug; ELISA: enzyme-linked immunosorbent assay; IL: interleukin; IV: intravenous; LTa: Iymphotoxin a; mAb: monoclonal antibody; MAD: multiple ascending dose; MTX: methotrexate; PD: pharmacodynamics; PK: pharmacokinetics; RA: rheumatoid arthritis; RF: rheumatoid factor; SAD: single ascending dose; SC: subcutaneous; SJC: swollen joint count; $t_{1 / 2}$ : terminal half-life; TNF-a: tumor necrosis factor $a$; TJC: tender joint count.
\end{abstract}

\section{Acknowledgements}

We thank the patients and investigators who participated in this study. From Genentech, we thank Cynthia Woods and Audi Meyer for their assistance in bioanalytical analysis of soluble LT $\alpha$, CXCL13, PK, and ATA analysis, Franklin Fuh for coordinating analysis of PD analyses, Yanan Zheng for preliminary population PK analysis and Eugene Chiang, Judy Young and Krista McCutcheon for antibody support. Study sponsorship and medical writing support were provided by Genentech.

\section{Author details}

Genentech, Inc, 1 DNA Way, South San Francisco, CA 94080, USA.

${ }^{2}$ Polyclinic of the Hospital Brothers of St John of God in Budapest, 114 PO Box 54, Budapest H-1525, Hungary. ${ }^{3}$ University of California at San Francisco, Box 0558, 185 Berry Street 5300, San Francisco, CA 94107, USA.

\section{Authors' contributions}

BE served as a medical monitor, performed data analysis and drafted the manuscript. DL was responsible for data management, performed data analysis and drafted the manuscript. CO participated in trial design and execution and reviewed the manuscript. JG generated the molecule under study, served as scientific advisor and drafted the manuscript. MW generated the PD data, performed data analysis and drafted the manuscript. MT performed PK/ATA data analysis and reviewed the manuscript. JX performed PK/ATA data analysis and drafted the manuscript. JL participated in trial design, served as a medical monitor, performed data analysis and reviewed the manuscript. JD participated in trial design, performed data analysis and drafted the manuscript. BR was the principal investigator, performed data review and reviewed the manuscript. All authors read and approved the final manuscript. 


\section{Competing interests}

$B E, D L, C O, J G, M W, M T, J X, J L$ and JD are or were employees of Genentech during the study. BR declares an advisory relationship with Genentech. Genentech funded the study and oversaw the collection of data, but the data analysis and interpretation were performed with the assistance of expert advisors.

Received: 19 August 2011 Revised: 7 November 2011

Accepted: 8 January 2012 Published: 8 January 2012

\section{References}

1. Sfikakis PP: The first decade of biologic TNF antagonists in clinical practice: lessons learned, unresolved issues and future directions. Curr Dir Autoimmun 2010, 11:180-210.

2. Bongartz T, Sutton AJ, Sweeting MJ, Buchan I, Matteson EL, Montori V: AntiTNF antibody therapy in rheumatoid arthritis and the risk of serious infections and malignancies: systematic review and meta-analysis of rare harmful effects in randomized controlled trials. JAMA 2006, 295:2275-2285.

3. Edwards JC, Szczepanski L, Szechinski J, Filipowicz-Sosnowska A, Emery P, Close DR, Stevens RM, Shaw T: Efficacy of B-cell-targeted therapy with rituximab in patients with rheumatoid arthritis. N Engl I Med 2004, 350:2572-2581.

4. Gramaglia I, Mauri DN, Miner KT, Ware CF, Croft M: Lymphotoxin $\alpha \beta$ is expressed on recently activated naive and Th1-like CD4 cells but is down-regulated by IL-4 during Th2 differentiation. J Immunol 1999, 162:1333-1338.

5. Ware CF: Network communications: lymphotoxins, LIGHT, and TNF. Annu Rev Immunol 2005, 23:787-819.

6. Chiang EY, Kolumam GA, Yu X, Francesco M, Ivelja S, Peng I, Gribling P. Shu J, Lee WP, Refino CJ, Balazs M, Paler-Martinez A, Nguyen A, Young J, Barck KH, Carano RA, Ferrando R, Diehl L, Chatterjea D, Grogan JL: Targeted depletion of lymphotoxin-a-expressing TH1 and TH17 cells inhibits autoimmune disease. Nat Med 2009, 15:766-773.

7. Browning $\mathrm{JL}$ : Inhibition of the lymphotoxin pathway as a therapy for autoimmune disease. Immunol Rev 2008, 223:202-220.

8. Timmer TC, Baltus B, Vondenhoff M, Huizinga TW, Tak PP, Verweij CL, Mebius RE, van der Pouw Kraan TC: Inflammation and ectopic lymphoid structures in rheumatoid arthritis synovial tissues dissected by genomics technology: identification of the interleukin-7 signaling pathway in tissues with lymphoid neogenesis. Arthritis Rheum 2007, 56:2492-2502.

9. Weyand $\mathrm{CM}$, Seyler TM, Goronzy JJ: B cells in rheumatoid synovitis. Arthritis Res Ther 2005, 7(Suppl 3):S9-S12.

10. Young J, Yu X, Wolslegel K, Nguyen A, Kung C, Chiang E, Kolumam G, Wei N, Wong WL, DeForge L, Townsend MJ, Grogan JL: Lymphotoxin- $\alpha \beta$ heterotrimers are cleaved by metalloproteinases and contribute to synovitis in rheumatoid arthritis. Cytokine 2010, 51:78-86.

11. Takemura S, Braun A, Crowson C, Kurtin PJ, Cofield RH, O'Fallon WM, Goronzy JJ, Weyand CM: Lymphoid neogenesis in rheumatoid synovitis. J Immunol 2001, 167:1072-1080.

12. Gommerman JL, Browning JL: Lymphotoxin/light, lymphoid microenvironments and autoimmune disease. Nat Rev Immunol 2003, 3:642-655.

13. Weyand CM: Immunopathologic aspects of rheumatoid arthritis: who is the conductor and who plays the immunologic instrument? I Rheumatol Supp/ 2007, 79:9-14.

14. Arnett FC, Edworthy SM, Bloch DA, MCShane DJ, Fries JF, Cooper NS, Healey LA, Kaplan SR, Liang MH, Luthra HS, Medsger TA Jr, Mitchell DM, Neustadt DH, Pinals RS, Schaller JG, Sharp JT, Wilder RL, Hunder GG: The American Rheumatism Association 1987 revised criteria for the classification of rheumatoid arthritis. Arthritis Rheum 1988, 31:315-324.

15. Wang H, Cain G, Kaiser R, McBride J, Lutman J, Grogan J, Gelzleichter T, lyer $\mathrm{S}$ : Evaluation of a humanized monoclonal antibody targeting lymphotoxin a in non-human primates. Ann Rheum Dis 2010, 69:181.

16. Shi K, Hayashida K, Kaneko M, Hashimoto J, Tomita T, Lipsky PE, Yoshikawa H, Ochi T: Lymphoid chemokine B cell-attracting chemokine-1 (CXCL13) is expressed in germinal center of ectopic lymphoid follicles within the synovium of chronic arthritis patients. J Immunol 2001, 166:650-655.

17. Rosengren S, Wei N, Kalunian KC, Kavanaugh A, Boyle DL: CXCL13: a novel biomarker of B-cell return following rituximab treatment and synovitis in patients with rheumatoid arthritis. Rheumatology (Oxford) 2011, 50:603-610

18. Rioja I, Hughes FJ, Sharp CH, Warnock LC, Montgomery DS, Akil M, Wilson AG, Binks MH, Dickson MC: Potential novel biomarkers of disease activity in rheumatoid arthritis patients: CXCL13, CCL23, transforming growth factor $a$, tumor necrosis factor receptor superfamily member 9 , and macrophage colony-stimulating factor. Arthritis Rheum 2008, 58:2257-2267.

19. Meeuwisse $C M$, van der Linden MP, Rullmann TA, Allaart CF, Nelissen $R$, Huizinga TW, Garritsen A, Toes RE, van Schaik R, van der Helm-van Mil AH: Identification of CXCL13 as a marker for rheumatoid arthritis outcome using an in silico model of the rheumatic joint. Arthritis Rheum 2011, 63:1265-1273.

20. Genovese MC, Greenwald MW, Alloway JA, Baldassare AR, Chase W, Newman C, Weaver ML: Efficacy and safety of Baminercept in the treatment of rheumatoid arthritis (RA): results of the phase $2 B$ study in the TNF-IR population [abstract]. Arthritis Rheum 2009, 60(Suppl 10):417.

21. Isaacs JD, Genovese MC, Emery P, Scheinberg MA, Spindler AJ, Newman C, Weaver ML: Efficacy and safety of Baminercept in the treatment of rheumatoid arthritis (RA): preliminary results of the phase $2 B$ study in the DMARD-IR population [abstract]. Arthritis Rheum 2009, 60(Suppl 10):416.

22. Grogan JL: Novel mechanism of action for anti-lymphotoxin-a in autoimmune disease: depletion of Th1 and Th17 cells [abstract]. In Advances in TNF Family Research (Advances in Experimental Medicine and Biology), Proceedings of the 12th International TNF Conference, 2009. Edited by: Wallach D, Kovalenko A, Feldmann M. New York: Springer; 2011:723.

\section{doi:10.1186/ar3554}

Cite this article as: Emu et al.: Safety, pharmacokinetics, and biologic activity of pateclizumab, a novel monoclonal antibody targeting lymphotoxin $\alpha$ : results of a phase I randomized, placebo-controlled trial. Arthritis Research \& Therapy 2012 14:R6.

\section{Submit your next manuscript to BioMed Central and take full advantage of:}

- Convenient online submission

- Thorough peer review

- No space constraints or color figure charges

- Immediate publication on acceptance

- Inclusion in PubMed, CAS, Scopus and Google Scholar

- Research which is freely available for redistribution

Submit your manuscript at www.biomedcentral.com/submit
C Biomed Central 